\title{
Cactus (Opuntia ficus-indica): A Review on its Antioxidants Properties and Potential Pharmacological Use in Chronic Diseases
}

Ulises Osuna-Martínez ${ }^{1}$, Jorge Reyes-Esparza² and Lourdes Rodríguez-Fragoso ${ }^{2 *}$

${ }^{1}$ Autonomous University of Sinaloa, Faculty of Biological and Chemical Sciences, Cualiacan, Mexico

${ }^{2}$ Autonomous University of Morelos State, Faculty of Pharmacy, Cuernavaca, Mexico

\begin{abstract}
Cactus (Opuntia ficus-indica) has been used in traditional folk medicine because of its role in treating a number of diseases and conditions, including diabetes, hypertension, hypercholesterolemic, rheumatic pain, gastric mucosa diseases and asthma, in many countries over the world. Nowadays, the cactus, fruits and cladodes, is the focus of many studies because they contain bioactive (phytochemicals) compounds, well known for their health-related properties. It has been revealing a positive correlation between a diet rich in prickly pear cactus and a reduced risk of diseases associated with oxidative stress, such as diabetes, cancer, cardiovascular and neurodegenerative diseases. The Opuntia ficus-indica exhibits diverse pharmacological actions through its antioxidant activity: protects cells against oxidative damage, acts as radical scavengers, reduces lipid peroxidation and increases GSH levels. So far, there is no report about the adverse/toxic effects on humans. This review provides clinical and experimental evidences about the most important phytochemical that contribute to its action hypoglycemic, hypolipidemic, hipocholesterolemic and neuroprotective in order to give the basis of their use in the prevention and cure of some chronic diseases. More studies on Opuntia ficus-indica could help better understand its pharmacological mechanism of action to provide clear scientific evidence to explain its traditional uses, and to identify its therapeutic potential in other diseases.
\end{abstract}

Keywords: Cactus; Opuntia ficus-indica; Antioxidant; Chronic diseases

Abbreviations: LDL-C: Low-density-lipoprotein cholesterol; HDL-C: High-density lipoprotein cholesterol; BPH: Benign prostatic hypertrophy; PARP: ADP ribose polymerase; $\mathrm{H}_{2} \mathrm{O}_{2}$ : Hydrogen peroxide; X: Xanthine; XO: Xanthine oxidase; BDNF: Brain-derived neurotrophic factor; pCREB: Phosphorylated cAMP response element binding-protein; pERK: Phosphorylated extracellular signal-regulated kinase; NO: Nitric oxide; ROS: Reactive oxygen species; GSH: Glutathione

\section{Introduction}

Today the world appears to be increasingly interested in the health benefits of foods and has begun to look beyond the basic nutritional benefits of foodstuffs to disease prevention. It is generally accepted that the beneficial effects of herbal remedies can be obtained from active constituents present in the whole plant, parts of the plant (e.g., flowers, fruits, roots or leaves), or plant materials or combinations thereof, whether in crude or processed state [1]. Cactus (Opuntia ficus-indica) commonly known as prickly pear belongs to the family Cactaceae. Opuntia ficusindica produces sweet, nutritionally rich edible fruits; its tender cladodes are used as fresh green vegetable and salad (Figure 1) [2,3].

According to previous reports, family Cactaceae is reported to contain about 130 genera and nearly 1500 all well adapted to arid lands and to a diversity of climates and are naturalized in several areas all over the world, including the Mediterranean basin, Middle East, South Africa, Australia and India. In South Africa, Mediterranean areas and South American this species is also cultivated for its edible fruit (prickly pear), although in some countries different parts of the plant are utilized in the food and cosmetic industry [4-6].

Opuntia ficus-indica, fruits and stems, have been traditionally used in folk medicine in several countries for several medicinal purposes $[7,8]$. However, many researchers have focused his investigations for studying genus Opuntia in order to discover the properties of plant that could form the basis of their use in the prevention and cure of chronic diseases (Table 1). Therefore clinical pharmacologic interest in the efficacy and safety of the phytochemicals present in genus Opuntia has grown during recent years due to the realization that many people self- medicate using this plant. Here we provide clinical and experimental evidences about the effects of phytochemical from Opuntia ficus-indica on health in order to give some ideas of the potential benefits of one commonly used plant around the world.

\section{Nutritional content and bioactive chemical constituents of Opuntia ficus-indica}

The main constituent of Opuntia ficus-indica cladodes is water (80$95 \%)$, followed by small amounts of carbohydrates (3-7\%), fiber (1-2\%),
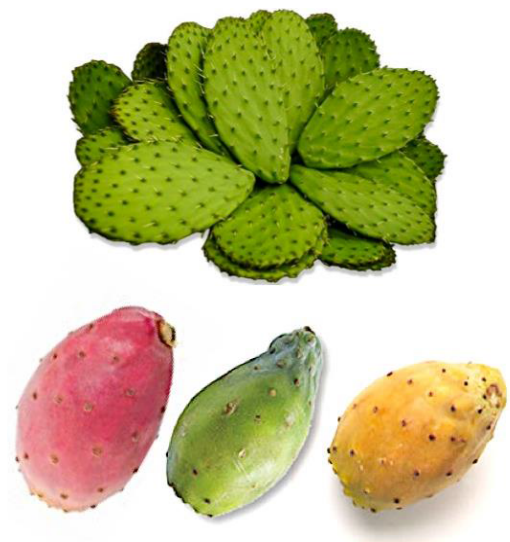

Figure 1: Opuntia ficus-indica (L), fruits and cladodes.

*Corresponding author: Lourdes Rodríguez-Fragoso, Autonomous University of Autonomous University of Morelos State, Faculty of Pharmacy. Cualiacan Mexico, Tel: 52-777-329-7089; E-mail: mrodriguezf@uaem.mx

Received September 17, 2014; Accepted October 14, 2014; Published October 16,2014

Citation: Osuna-Martínez U, Reyes-Esparza J, Rodríguez-Fragoso L (2014 Cactus (Opuntia ficus-indica): A Review on its Antioxidants Properties and Potential Pharmacological Use in Chronic Diseases. Nat Prod Chem Res 2: 153. doi:10.4172/2329-6836.1000153

Copyright: () 2014 Osuna-Martínez U, et al. This is an open-access article distributed under the terms of the Creative Commons Attribution License, which permits unrestricted use, distribution, and reproduction in any medium, provided the original author and source are credited. 
Citation: Osuna-Martínez U, Reyes-Esparza J, Rodríguez-Fragoso L (2014) Cactus (Opuntia ficus-indica): A Review on its Antioxidants Properties and Potential Pharmacological Use in Chronic Diseases. Nat Prod Chem Res 2: 153. doi:10.4172/2329-6836.1000153

Page 2 of 8

\begin{tabular}{|c|c|c|c|}
\hline Scientific names Opuntia ficus-indica & Common names & Cultural uses & Pharmacological uses \\
\hline $\begin{array}{l}\text { Synonyms: } \\
\text { Opuntia vulgaris, } \\
\text { Opuntia compressa, Opuntia maxima, Opuntia cordobensis, } \\
\text { Opuntia tuna-blanca } \\
\text { Cactus opuntia, } \\
\text { Cactus compressus, } \\
\text { Platyopuntia vulgaris, Platyopuntia cordobensis, }\end{array}$ & $\begin{array}{l}\text { Indiang fig } \\
\text { Barbary fig } \\
\text { Tuna cactus } \\
\text { Cactus pear } \\
\text { Nopal } \\
\text { Mission cactus } \\
\text { Smooth mountain } \\
\text { Prickly pear }\end{array}$ & $\begin{array}{l}\text { Treatment of diabetes, hypertension, } \\
\text { hypolipidemic, } \\
\text { asma, ulcers, rheumatic pain, wounds, } \\
\text { and fatigue }[1,3,5,6,15,26] \text {. }\end{array}$ & $\begin{array}{l}\text { Anti-diabetic [30-34,37,38] } \\
\text { Anti-hypercholesterolemic [43] } \\
\text { Anti-hyperlipidemic [43] } \\
\text { Anti-stress [45] } \\
\text { Anti-uric and diuretic [47] } \\
\text { Anti-inflammatory [49] } \\
\text { Anti-cancer [50] } \\
\text { Neuroprotector [52-55] }\end{array}$ \\
\hline
\end{tabular}

Table 1: Traditional uses and pharmacological properties of Opuntia ficus-indica

and protein $(0.5-1 \%)$; other compounds are only partly known and have not been quantitatively determined [9]. The sugar moiety includes mucilaginous components containing polymers, such as chains of (1-4)-linked $\beta$-D-galacturonic acid and $\mathrm{R}(1-2)$-linked L-rhamnose residues $[10,11]$. The physiological role of the plant mucilage is to regulate the cellular water content during prolonged drought and to regulate the calcium fluxes of the plant $[12,13]$. Opuntia ficus-indica cladodes also represent a source of phytochemicals, such as phenolics acids and flavonoids (Figure 2) [14].

Cactus dietary fiber is composed of several chemical components that are resistant to digestive enzymes such as cellulose, hemicelluloses, pectin, lignin, gums, etc. [15]. The benefits associated with fiber content are well known, especially for the prevention of illnesses such as diabetes, treatment of gastrointestinal disorders, illnesses associated with low dietary fiber intake, reduction of glucose values in the blood, anti-hyperlipidemic and anti-hypercholesterolemic effects [16]. Throughout history, the benefits of consuming dietary fiber have been recognized. Soluble fibers, including pectins, gums, and mucilages, increase the viscosity of food in the gut, slowing or reducing sugar absorption. The effect of soluble fiber in reducing serum glucose concentrations is a proposed mechanism of action for the herbal hypoglycemic cactus [1,17]. It has been reported that Opuntia ficusindica contain phenolic compounds like ferulic acid, feruloyl-sucrose and sinapoyl-diglucoside, fatty acids like palmitic acid, stearic acid, oleic acid, vaccenic acid and linoleic acid (seeds, peel and juicy pulp) [18]. It has been observed that Opuntia ficus-indica oil extract with these components present antioxidant and anti-free radical activity, having a potential as anticancer, anti-inflammatory, hypoglycemic, hypolipidemic and hypocholesterolemic activities [19]. Recently was reported that cactus fiber promote fecal fat excretion, Uebelhack et al. performed a double-bind, randomized, placebo-controlled, crossover study in healthy subjects for a period of approximately 45 days. Cactus fiber tablet contains $500 \mathrm{mg}$ standardized cactus fiber; as well as common tableting excipients were used. Cactus fiber showed an increased fecal fat excretion compared with placebo. No adverse events were reported throughout the study period [20].

Opuntia ficus-indica was found to have various classes of bioactive compounds (Figure 2) [12,21]. It has been established that the amount of phytochemicals varies between genus Opuntia; for example, it has been demonstrated that red-skinned prickly pear fruits contain taurine (7.7-11.2 mg/100g fresh fruit) at the same level of Sicilian cultivars of Opuntia ficus-indica but at a lower concentration than that reported for American and African cultivars [22]. It has been observed the presence of total phenolic and polyphenolic compounds (free and conjugated) in concentrations of $80-90 \mathrm{mg} / 100 \mathrm{~g}$ dried weight, which include aromadendrin, taxifolin or dihydroquercetin, isorhamnetin, vitexin, kaempferol, quercetin, betalains, betacyanins, rutin and isorhamnetin and derivatives like myricetin, orientin and some derivatives of pyrone [23]. A great deal of plant essential oils has beneficial properties such as antioxidant and antimicrobial activities, among other, [24,25] and the presence of antioxidant and antimicrobial compounds found in this study

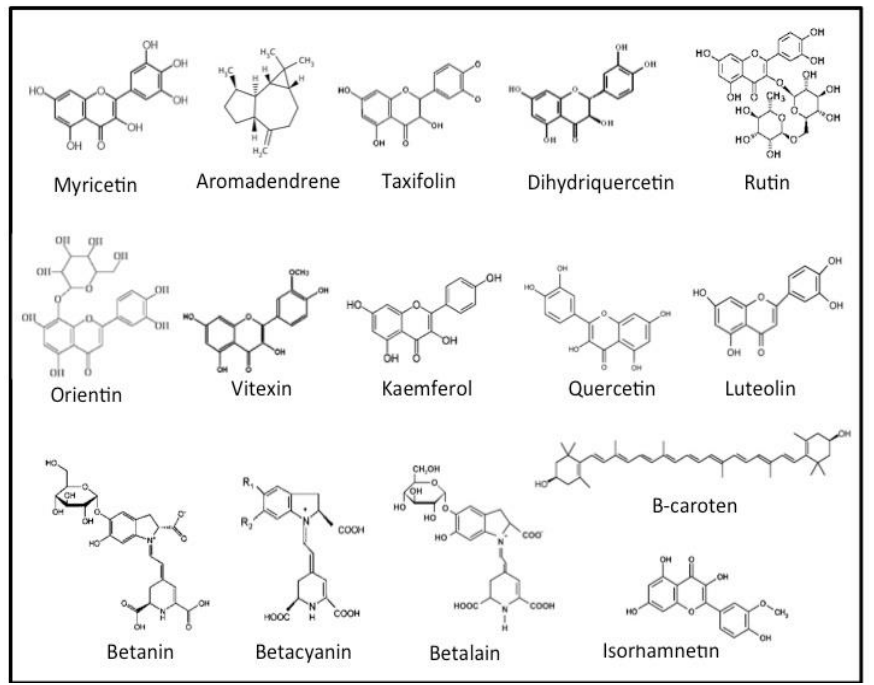

Figure 2: Structures of most important phytochemicals found in Opuntia ficusindica $(\mathrm{L})$.

increases the value of Opuntia ficus-indica. The seeds of Opuntia ficusindica growing have also shown to have an appreciable amount of oil with high level of unsaturated fatty acids which are healthy benefic [18].

\section{Pharmacological effects and mechanism of action of Opuntia ficus-indica}

Clinical and experimental evidence suggests that Opuntia ficus-indica might be useful for treating some chronic diseases (Tables 2 and 3 ).

\section{Metabolic syndrome}

Metabolic syndrome describes the increasing incidence of type 2 diabetes in association with obesity, hyperinsulinemia associated with disorders of metabolism of carbohydrates and lipids. Diabetes mellitus represents one of the biggest problems in public health. An alternative for its control is found in medicinal plants. Plants in the genus Opuntia are the most clinically and experimentally studied. Traditional preparations from those species have been evaluated in temporarily hyperglycemic rabbits, in alloxan-diabetic rabbits, type II diabetic patients and normal volunteers [26-32]. In a crossover, placebo-controlled human study of eight patients with Type 2 Diabetes, Roman-Ramos et al. [33] compared serum glucose levels after patients consumed 500 grams of broiled cactus stems and crude extracts. Serum glucose levels using crude raw extracts were not modified. However, the intake of broiled plant stems caused a decrease in serum glucose levels of $48.3 \pm 16.2 \mathrm{mg} / \mathrm{dL}$ versus basal levels at $3 \mathrm{~h}$ post-ingestion. The authors suggested that heating might be necessary to achieve a hypoglycemic effect.

Opuntia ficus-indica dehydrated leaves can be consumed as a 
Citation: Osuna-Martínez U, Reyes-Esparza J, Rodríguez-Fragoso L (2014) Cactus (Opuntia ficus-indica): A Review on its Antioxidants Properties and Potential Pharmacological Use in Chronic Diseases. Nat Prod Chem Res 2: 153. doi:10.4172/2329-6836.1000153

Page 3 of 8

\begin{tabular}{|c|c|}
\hline Diseases & Evidences \\
\hline Metabolic syndrome & $\begin{array}{l}\text { Hyperglycemic rabbits, in alloxan-diabetic rabbits }[27,29,32] \text {. } \\
\text { Reducing cholesterol and LDL-C in hypercholesterolemic mice [43]. } \\
\text { Anti-atherogenic effects by decreasing NO amounts in hyperlipidemic mice, probably via its antioxidant effects and by reducing lipid } \\
\text { peroxidation in mice, as well as by increasing of NO amount and antioxidant enzyme superoxide dismutase (SOD), catalase (CAT) and } \\
\text { glutathione peroxidase (GPx) }[45,46]\end{array}$ \\
\hline Renal disease & $\begin{array}{l}\text { Increases the diuresis and natriuresis in rats [47]. } \\
\text { Diuretic and antiuric effects in rats via the increased excretion of sodium and potassium in urine [48]. }\end{array}$ \\
\hline Inflammatory disease & $\begin{array}{l}\text { Anti-inflammatory action in a chronic inflammation model in mice by suppressing the release of beta-glucuronidase, a lysosomal enzyme in rat } \\
\text { neutrophils [49]. }\end{array}$ \\
\hline Neoplastic disease & $\begin{array}{l}\text { Antiproliferative effects in vitro through the release of cytochrome c from mitochondria into the cytosol and ADP ribose polymerase (PARP) } \\
\text { cleavage [50]. } \\
\text { Exerts chemopreventive effects on chemical carcinogenesis in mouse skin via the modulation of cutaneous lipid peroxidation, enhancing total } \\
\text { antioxidant capacity, especially in phase II, detoxifying the enzyme system and having partial apoptotic influence [68]. }\end{array}$ \\
\hline Neuronal disease & $\begin{array}{l}\text { Induces neuroprotection through its inhibitory action on xanthine/xanthine oxidase (X/NO)in neuronal in vitro [52,53]. } \\
\text { Neuroprotects and enhances long-term memory by increasing the expression levels of brain-derived neurotrophic factor (BDNF), phosphorylated } \\
\text { cAMP response, element binding-protein (pCREB), and phosphorylated extracellular signal-regulated kinase (pERK) 1/2 in mice [54]. } \\
\text { Improves the cerebral ischemia by inhibiting NO production through the activation of microglial cells and peroxynitrite scavenging activity in } \\
\text { vitro and in vivo models [55]. } \\
\text { Antidepressant effect in mice by increasing the expression of the hypothalamic POMC mRNA and plasma } \beta \text {-endorphin level [57]. }\end{array}$ \\
\hline $\begin{array}{l}\text { Pathological process } \\
\text { associated with oxidative } \\
\text { stress }\end{array}$ & $\begin{array}{l}\text { Protects against ethanol-induced damage in rat erythrocytes by increasing scavenger activity }[19,62] \text {. } \\
\text { Protects liver cells due to its scavenging activity against G/GO-induced radical production }[64] \text {. } \\
\text { Antigenotoxic and anti-apoptotic effects due its protective action in terms of generation of oxidative stress, genomic DNA integrity and modulate } \\
\text { apoptosis status in mice [65]. } \\
\text { Protects against oxidative damage due to the reductionof lipid peroxidation by enhancing total antioxidant capacity, especially in phase II, } \\
\text { detoxifying the enzyme system [68]. }\end{array}$ \\
\hline
\end{tabular}

Table 2: Experimental evidences of pharmacological effects.

\begin{tabular}{|c|c|}
\hline Diseases & Evidences \\
\hline Metabolic syndrome & $\begin{array}{l}\text { Anti-hyperglycemic effect occurs at doses of } 100 \mathrm{mg} / \mathrm{kg} \text { in Type II diabetic patients and normal volunteers; the mode of action is not yet known [33]. } \\
\text { Anti-hyperglycemic effect in placebo-controlled human study of eight patients with Type } 2 \text { Diabetes; the mode of action is not described [34]. } \\
\text { Decrease of LDL-C and increase of HDL-C in a randomized, placebo-controlled, double-blind trial with women suffering from metabolic syndrome; } \\
\text { the mode of action is not described [35]. } \\
\text { Reduction of postprandial blood glucose, serum insulin and plasma glucose-dependent insulinotropic peptide in patients with type } 2 \text { diabetes; the } \\
\text { mode of action is not yet known [36]. } \\
\text { Reduction of blood glucose levels in a clinical trial with obese, pre-diabetic adults [37]. } \\
\text { Stimulates peripheral disposal of glucose before and after exercise in healthy men by increasing plasma insulin and facilitating the clearance of an } \\
\text { oral glucose load from circulation [38]. } \\
\text { Insulinogenic effect in healthy volunteers when combined with leucine; authors suggest that Opuntia ficus-indica combined with leucine increased } \\
\text { the rate of glucose appearance from the gut and liver, as well as the rate of disappearance through peripheral glucose uptake, resulting in unchanged } \\
\text { blood glucose concentrations [39]. } \\
\text { Weight loss in overweight and obese patients, randomized, double blind, placebo-controlled trial; the mode of action is not described [41]. }\end{array}$ \\
\hline Neoplastic disease & Improves symptoms of benign prostatic hypertrophy (BPH); the mode of action is not yet known [51]. \\
\hline $\begin{array}{l}\text { Pathological process } \\
\text { associated with } \\
\text { oxidative stress }\end{array}$ & $\begin{array}{l}\text { Antioxidant effect in healthy people and patients with type } 2 \text { diabetes; the mode of action is not yet known [36]. } \\
\text { Positively affects the body's redox balance by decreasing oxidative damage to lipids and improves antioxidant status in healthy humans [44]. } \\
\text { Antioxidant effect on healthy volunteers after } 3 \text { days of Opuntia ficus-indica consumption; the mode of action is not described [69]. }\end{array}$ \\
\hline Alcoholism & Reduction of symptoms of alcohol hangover by decrease of C-reactive protein levels, double-blind, placebo-controlled, cross-over trial [70]. \\
\hline Other diseases & $\begin{array}{l}\text { Increase of bone mineral density and reduction of calciuria, longitudinal, quasi-experimental, blind and randomized 2-years temporary study; high } \\
\text { amount of calcium in dehydrated Opuntia ficus-indica could be acting as a supplementary resource [72]. } \\
\text { Increase of fecal fat excretion by the fat-binding capability of cactus fiber; double-blind, randomized, placebo-controlled, crossover study [75]. }\end{array}$ \\
\hline
\end{tabular}

Table 3: Clinical evidences of pharmacological effects.

dietary supplement to improve some blood lipids parameters and risk factors in the case of metabolic syndrome. A monocentric, randomized, placebo-controlled, double-blind study was performed on 68 women suffering from metabolic syndrome and having a body mass index between 25 and 40. Dehydrated leaves of Opuntia ficusindica or placebo capsules were taken at a dosage of $1.6 \mathrm{~g}$ per meal. All 5 metabolic syndrome criteria were measured, including LDL-C, HDL-C and triglyceride levels. This study reported a significant increase in HDL-C levels upon consumption of dehydrated Opuntia ficus-indica leaves and a tendency toward decreased triglyceride levels. Fortytwo females taking dehydrated leaves of Opuntia ficus-indica with no additional hypolipemic treatment showed a pronounced reduction in LDL-C, especially after day 14 . At the end of the study, $39 \%$ of the women in the group administered dehydrated Opuntia ficus-indica leaves were no longer diagnosed with metabolic syndrome. This was the case for only $8 \%$ of the placebo group [34].
Recently, López-Romero et al. [35] reported that consumption of Opuntia ficus-indica could reduce postprandial blood glucose, serum insulin, and plasma glucose-dependent insulinotropic peptide peaks, as well as increase antioxidant activity in healthy people and patients with type 2 diabetes. Two different studies were performed. In study 1 , the glycemic index, insulinemic index, glucose-dependent insulinotropic peptide index, and glucagon-like peptide 1 index were calculated for seven healthy participants who consumed $50 \mathrm{~g}$ of available carbohydrates from glucose or dehydrated Opuntia ficusindica. In study 2, 14 patients with type 2 diabetes consumed Opuntia ficus-indica in a high-carbohydrate breakfast or high-soy-protein breakfast with or without $300 \mathrm{~g}$ of steamed nopal. The glycemic index of nopal was $32.5 \pm 4$, its insulinemic index was $36.1 \pm 6$, the glucosedependent insulinotropic peptide index was $6.5 \pm 3.0$, and the glucagonlike peptide 1 index was $25.9 \pm 18$. Patients with type 2 diabetes who consumed the high-carbohydrate breakfast + Opuntia ficus-indica 
showed a significantly lower area under the curve for glucose than those who consumed the high-carbohydrate breakfast only. Patients who consumed Opuntia ficus-indica with their high-carbohydrate breakfast also showed a lower incremental area under the curve for insulin, while those patients with type 2 diabetes who consumed the high-soy-protein breakfast avoided postprandial blood glucose peaks. Consumption of the high-soy-protein breakfast + Opuntia ficus-indica significantly reduced the postprandial peaks of glucose-dependent insulinotropic peptide concentration at 30 and 45 minutes and increased antioxidant activity after 2 hours, measured by the 2,2-diphenyl-1-picrilhidracyl method [35].

A clinical trial evaluated the acute and chronic effects of cactus in obese, pre-diabetic men and women and found acute blood glucose lowering effects and the long-term safety of the cactus, supporting its traditional use for blood glucose management [36]. On the other hand, it was evaluated the effect of Opuntia ficus-indica cladode and fruitskin extract on blood glucose and plasma insulin increments due to high-dose carbohydrate ingestion, before and after exercise. It was also found Opuntia ficus-indica cladode and fruit-skin extract increased plasma insulin and thereby facilitated the disposal of an oral glucose load from the circulation. This reduction in blood glucose was more explicit after exercise than in a basal state [37].

The interaction between Opuntia ficus-indica and the insulinogenic effect has also been studied. A randomized double-blind cross-over study with healthy, physically active males showed that $1000 \mathrm{mg}$ of Opuntia ficus-indica extract $+3 \mathrm{~g}$ leucine increased plasma insulin concentration after exercise and thereby potentially accelerated glycogen resynthesis. The authors have suggested that Opuntia ficusindica combined with leucine increased the rate of glucose appearance from the gut and liver, as well as the rate of disappearance through peripheral glucose uptake that resulted in unchanged blood glucose concentrations [38]. As the decreases were equal in amplitude, it was suggested that amino acids-induced insulin stimulation accelerates glycogen resynthesis after exercise by increasing glycogen synthase activity rather than by increasing muscle glucose uptake [39]. However, further studies should try to determine whether the higher circulating insulin levels established by combining Opuntia ficusindica with leucine during high rate glucose uptake post exercise effectively translate into higher glycogen synthase activity and glycogen resynthesis rate following exercise [38].

A randomized, double blind, placebo-controlled trial with 30 males and 93 females suffering from overweight and obesity was conducted to research the efficacy of Litramine IQP-G-002AS, a dietary fiber derived from Opuntia ficus-indica, in reducing body weight. The subjects consumed either $3 \mathrm{~g}$ /day of Litramine IQP-G-002AS or placebo tablets for 12 weeks. Results showed a statistically significant increase in total weight loss (2.4 kg more) among the Litramine IQPG-002AS group when compared to the placebo group ( $3.8 \mathrm{~kg}$ (SD $1.8 \mathrm{~kg}$ ) versus $1.4 \mathrm{~kg}$ $(\mathrm{SD} 2.6 \mathrm{~kg}) ; P<0.001)$. Furthermore, subjects treated with Litramine IQP-G-002AS also showed a significantly increased reduction in body fat composition $(0.7 \%$ (SD 1.7\%) versus $+0.1 \%$ (SD 2.5\%); difference $0.8 \% ; P<0.031)$ and waist circumference $(3.9 \mathrm{~cm}(\mathrm{SD} 2.7 \mathrm{~cm})$ versus $2.2 \mathrm{~cm}(\mathrm{SD} 2.9 \mathrm{~cm})$; difference $1.7 \mathrm{~cm} ; P<0.001)$ when compared to the placebo group [40]

Another study with healthy volunteers tried to elucidate the dietary fat binding capacity of Opuntia ficus-indica trough determination of fecal fat excretion. Uebelhack et al. [20] performed a double-blind, randomized, placebo-controlled, crossover study for 45 days. The administration of 2 tablets (500 $\mathrm{mg}$ each) of dehydrated cladode of
Opuntia ficus-indica as a supplement with a standardized diet increased dietary fat excretion in the feces when compared with the placebo. The authors suggest this confirms the in vivo fat-binding capability of cactus fiber and, furthermore, supports the hypothesis that its weight loss effect is achieved by reducing dietary fat absorption, which leads to lower energy intake and promotes weight loss.

Recently, it was reported that supplementation with methanolic extract from Opuntia joconostle seeds that are rich in antioxidant compounds was effective in reducing cholesterol and LDL-C in hypercholesterolemic mice [41]; authors suggest that this methanolic extract has potential to be included in short-term hypercholesterolemia treatment regimens because it exhibited hypolipidemic activity with no apparent toxic manifestations. On the other hand, it appears that pectin is able to alter hepatic cholesterol metabolism without affecting cholesterol absorption. Besides of that, it has been observed that consumption of prickly pear fruit positively affects the body's redox balance, decreases oxidative damage to lipids, and improves antioxidant status in healthy humans [42].

Anti-atherogenic effects have also been reported. The administration of Opuntia ficus-indica glycoprotein decreased NO amounts in hyperlipidemic mice, probably via its antioxidant effects and by reducing lipid peroxidation [43]. It has been also found that Opuntia ficus-indica var. saboten significant decreased of plasma lipid levels in Triton WR-1339-treated mice such as total cholesterol (TC), triglyceride (TG), and low-density lipoprotein (LDL) [44]. Therefore, clinical and experimental studies suggest that Opuntia ficus-indica possesses potential hypoglycemic, hypolipidemic and hypocholesterolemic effects, and has the potential for being used in the treatment of metabolic syndrome.

\section{Renal disease}

Perfumi and Tacconi [45] previously reported that flower infusion shows a modest increase in diuresis and natriuresis. However, Galati and others [46] studied the diuretic and antiuric effects of cladode and flower infusions in rats. They found that increased diuresis but do not significantly influence the uric acid pattern. This effect was more marked with the fruit infusion and it was particularly significant during the chronic treatment [5].

\section{Inflammatory disease}

In addition, Park et al. [47] reported analgesic and anti-inflammatory activity for fruit and stem extracts, and isolated $\beta$-sitosterol as an active anti-inflammatory principle from the stem extract. Both the extracts inhibited the writhing syndrome induced by acetic acid, indicating that they contain an analgesic effect. Moreover, the extracts suppressed the release of beta-glucuronidase, a lysosomal enzyme in rat neutrophils. It was also noted that the extracts had a protective effect on gastric mucosal layers.

\section{Neoplastic diseases}

It has been found that cactus has also anticancer effects. It has been demonstrated that betanin induces apoptosis in K562 cells through the intrinsic pathway and is mediated by the release of cytochrome $\mathrm{c}$ from mitochondria into the cytosol and ADP ribose polymerase (PARP) cleavage. The antiproliferative effects of betanin add further value to the nutritional characteristics of the cactus fruit [48]. On the other hand, previous studies suggest that the consumption of powdered prickly pear cactus flowers $500 \mathrm{mg} /$ day for 2-8 months improves symptoms such as urgency and feelings of fullness in the bladder in some patients with benign prostatic hypertrophy (BPH) [49]. 


\section{Neuronal disease}

Previous reports have shown that methanol extract of the fruits of Opuntia ficus-indica var. saboten inhibit free radical induced neuronal injury in mouse cortical cultures [50]. It was also reported that, in addition to the fruit extract, the methanol extract of the stems also inhibited the oxidative injury induced by $\mathrm{H}_{2} \mathrm{O}_{2}$ or xanthine (X)/ xanthine oxidase $(\mathrm{XO})$ in rat cortical cell cultures [51]. Recent reports also revealed that the expression levels of brain-derived neurotrophic factor (BDNF), phosphorylated cAMP response element bindingprotein (pCREB), and phosphorylated extracellular signal-regulated kinase (pERK) 1/2 were significantly increased in hippocampal tissue after 7 days of Opuntia ficus-indica var. saboten administration. These results suggested that the subchronic administration of Opuntia ficus-indica var. saboten enhances long-term memory, and that this effect is partially mediated by extracellular signal regulated kinase, cAMP-response element-binding protein, and brain-derived neurotrophic factor (ERK-CREB-BDNF) signaling and the survival of immature neurons [52]. Kim et al. [53] reported that Opuntia ficus-indica attenuates neuronal injury in vitro and in vivo models of cerebral ischemia. It seems methanol extract of Opuntia ficus-indica ameliorates the neuronal damage that occurs following ischemic insult by inhibiting nitric oxide (NO) production by activated microglial cells and peroxynitrite scavenging activity [54]. Another study has described the antidepressant effect of two flavonoids (kaempferol and quercetin) isolated from the Opuntia ficus-indica var. saboten [55].

\section{Antioxidant activity}

Over the past decades, we have discovered that reactive oxygen species (ROS) exert a multiplicity of biological effects across a wide spectrum that ranges from physiological regulatory functions to damaging alterations involved in the pathogenesis of an increasing number of diseases. Cumulative evidence found over the years clearly supports the idea that ROS and oxidants are important factors in many different pathological processes [56]. It is generally accepted that the beneficial effects of medicinal plants can be obtained from active constituents present in the whole plant, parts of the plant (e.g., flowers, fruits, roots or leaves), or plant materials or combinations thereof, whether in crude or processed state [1]. It has also been proposed that the additive and synergistic effects of phytochemicals in herbal remedies are responsible for their antioxidants activities, and that the benefits of plant-based diets are in part attributable to the complex mixture of phytochemicals present in whole foods [57].

Nowadays, there is considerable interest in natural products endowed with antioxidant properties, one medicinal plant that has been proposed having interesting antioxidant activity and protective capacities due to the presence of components such as vitamins $\mathrm{C}$ and E, phenolics and other non-nutrient substances is Opuntia ficusindica $(L)$. It has been found that fruit juice contains a rich variety of natural antioxidants, many phenol compounds, ascorbic acid, betalains, betacyanins, and a flavonoid fraction that consists mainly of rutin and isorhamnetin derivatives [58,59]. A number of studies have revealed a positive correlation between a diet rich in plant-based foods and reduced risk of diseases associated with oxidative stress such as cancer and cardiovascular and neurodegenerative diseases. Opuntia ficus-indica fruit extract reportedly protected erythrocytes against lipid oxidation induced in vitro by ethanol [60]. Scavenging activity was restored in a dose dependent manner to near normal level in ethanolfed rats given prickly pear juice, and restoration of GSH levels was also observed [19]. The normalization of scavenging activity by prickly pear juice supplement could be due to the natural antioxidants, which could modulate the intrinsic imbalance between oxidant species and the antioxidant defense system.

Ascorbic acid is an important antioxidant and its content in prickly pear fruits is considerably higher than average ascorbic acid contents among some common fruits such as plums $(7 \mathrm{mg} / 100 \mathrm{~g}$ fresh fruit) nectarines ( $10 \mathrm{mg} / 100 \mathrm{~g}$ fresh fruit) or peaches $(9 \mathrm{mg} / 100 \mathrm{~g}$ fresh fruit). In the same work, authors reported ascorbic acid contributes up to $68 \%$ of the antioxidant activity of cactus juices [61]. All the Opuntia species tested had significant amounts of flavonoids, with quercetin followed by isorhamnetin, luteolin and kaempferol. These compounds are more efficient antioxidants than vitamins, since flavonoids, and phenolic compounds in general, are able to delay the pro-oxidative effects on proteins, DNA and lipids through the generation of stable radicals [19]. Opuntia ficus-indica glycoprotein did not have any cytotoxic effect and instead protected liver cells due to its scavenging activity against G/ GO-induced radical production [62]. These results show that Opuntia ficus-indica glycoprotein exerts antioxidant and cytoprotective effects in vitro, either directly or indirectly.

Recently was reported that cactus cladode extract exposure prior and post to cis-diammine dichloroplatinum-induced oxidative stress and genotoxicity provided near complete protection in terms of generation of oxidative stress, genomic DNA integrity and modulate apoptosis status in mice. Authors concluded that antioxidant of cactus cladode extract would support biological resistance to free radicals, suggesting the capacity of this extract to play a role in antigenotoxic and anti-apoptotic effects of cactus cladode extract [63]. On the other hand, it was found that pre and post-administration of cactus cladode extract with aflatoxin B significantly reduced this oxidative effect, which dropped to control level [64]. The protective effects of cactus cladode extract to prevent and protect against oxidative damage is certainly associated to the presence of several antioxidants such as ascorbic acid, vitamin E, carotenoids, reduced GSH, flavonoids and phenolic acids actually detected in fruits and vegetables of different varieties of cactus [65]. Recently, it was found that Opuntia-humifusa, member of the Cactaceae family exerted chemo preventive effects on chemical carcinogenesis in mouse skin and that prevention effects were associated with reduction of oxidative stress via the modulation of cutaneous lipid peroxidation, enhancing of total antioxidant capacity especially in phase II detoxifying enzyme system and partial apoptotic influence [66].

The antioxidant activity of Opuntia ficus-indica was recently tested by Ávila-Nava et al. [67]. 10 healthy participants consumed a diet poor in antioxidant components for 3 days. After that, they added $300 \mathrm{~g} /$ day of Opuntia ficus-indica to their meals for the span of 3 days; at the end of the study, blood samples were taken and a DPPH assay was done. The results for healthy subjects showed a significant increase in antioxidant activity due to the consumption of the $300 \mathrm{~g}$ of Opuntia ficus-indica for 3 days. This increase was of $20 \%$ in plasma and $5 \%$ in blood. The most significant result was in plasma (20\%) when compared with the activity shown in the sample obtained before the consumption of Opuntia ficus-indica.

\section{Alcoholism}

Different studies have evaluated the benefits of Opuntia ficus-indica in treating symptoms of alcohol hangover in humans. The severity of a hangover can be partly due to the inflammation and disruption of lipid metabolism homeostasis [68]. A double-blind, placebo-controlled, cross-over trial with 64 adult volunteers showed that the symptoms of the alcohol hangover are largely due to the activation of inflammation. The extract of the Opuntia ficus-indica has a moderate effect in 
reducing hangover symptoms, apparently by inhibiting the production of inflammatory mediators. In this randomized study, volunteers received 2 capsules of Opuntia ficus-indica extract and identical placebo, administered 5 hours before alcohol consumption. During 4 hours, subjects consumed up to $1.75 \mathrm{~g}$ of alcohol per kilogram of body weight. Hangover severity and overall well-being were assessed, and blood and urine samples were obtained the following morning. Symptoms like nausea, dry mouth and anorexia were reduced by the consumption of Opuntia ficus-indica. C-reactive protein levels were strongly associated with hangover severity; the mean symptom index was 4.1 (95\% confidence interval, 1.2-7.1; $\mathrm{P}=.007$ ) higher in subjects with morning C-reactive protein levels greater than $1.0 \mathrm{mg} / \mathrm{L}$. In addition, C-reactive protein levels were $40 \%$ higher after subjects consumed placebo [69].

However, the systematic search performed by Pittler et al. [69] suggests there is no compelling evidence to suggest that complementing food intake with Opuntia ficus-indica is effective for treating or preventing alcohol hangovers. Future studies should investigate the changes that occur during an alcohol-induced hangover.

\section{Other diseases and pharmacological effects}

Other reports suggest that Opuntia ficus-indica has a pharmacological effect in a variety of diseases. The improvement of bone mineral density and calciuria to prevent osteoporosis was reported by Aguilera-Berreiro et al. [70]. For this, a longitudinal, quasi-experimental, blinded and randomized 2-years temporary study was carried out with 181 women. The consumption of dehydrated Opuntia ficus-indica after six months reportedly improved calciuria levels and turned them back to normal, remaining constant for the rest of the treatment. Bone mineral density increased in the total hip and lumbar region in those groups who consumed $600 \mathrm{~g}$ of dehydrated Opuntia ficus-indica. The authors have suggested that the high amount of calcium in dehydrated Opuntia ficus-indica could be acting as a supplementary resource.

\section{Toxicology of Opuntia ficus indica}

Orally, Opuntia ficus-indica is usually well tolerated. However, it has been reported that it may cause mild diarrhea, nausea, increased stool volume, increased stool frequency, abdominal fullness, and headache and low colonic obstruction, in books of traditional folk medicine and case reports $[1,71,72]$. Although the public and some health care professionals believe that herbal medicines are relatively safe because

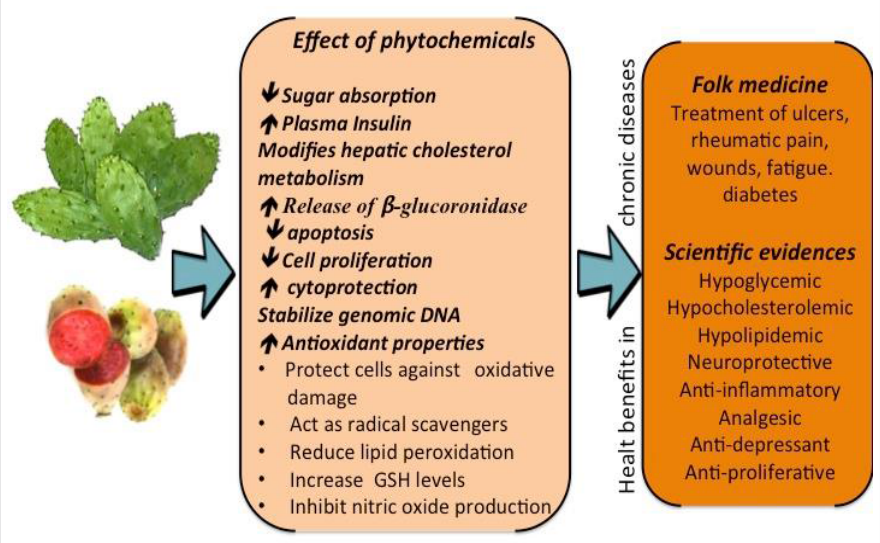

Figure 3: Hypothesis of the links between the working mechanisms of phytochemicals present in Opuntia ficus-indica $(L)$ and their effects on disease. they are "natural", there are remarkably little data to support this assumption. However, side effects may also occur due to contaminants in herbal products, as heavy metals, including lead, mercury, or arsenic, and other undeclared pharmaceuticals, purposefully and illegally added to the herbs to produce a desired effect [72]. In addition, there exist other factors that might also affect the content of active constituents in the herbal product (as microorganisms, microbial toxins, and genetic factors). All plant remedies contain chemical compounds that are considered potentially toxic and they are cited in the Hazardous Substances Data Bank (National Library of Medicine, Bethesda, Maryland), it is worthwhile to launch more investigations to evaluate the risks and benefits of using Opuntia ficus-indica.

\section{Conclusion}

Although modern medicine may be available in most countries for the treatment of many chronic degenerative diseases, folk medicine (phytomedicine) has remained popular for historical and cultural reasons. Despite the fact that Opuntia ficus-indica is commonly used around the world, there is a lack of in-depth study on the mechanism of action of pharmacological effects of its active ingredients. Few plant species that provide medicinal herbs have been scientifically evaluated for their possible medical applications. Due to a great number of potentially active nutrients from Opuntia ficus-indica, fruits and cladodes are claimed to be health-promoting food. This review presented evidence of the potential antioxidant properties of cactus or their components (phytochemicals) and their role in regulating and maintaining normal processes in living organisms. Natural antioxidants obtained from plant-based extracts of cactus are currently a subject of intensive research, and are of interest to both food scientists and health professionals. Preclinical and clinical information indicates that Opuntia ficus-indica is efficacious for certain chronic diseases (Figure 3).

There is a dearth in the field of pharmacodynamics and pharmacokinetics or safety aspects of the genus Opuntia. There have been very few studies pertaining to the molecular aspects of genus Opuntia, which is clearly evident by the sequence of information available in the public domains. Even though genus Opuntia is rich in healing properties, due to the lacunae in many aspects, there is an urgent requirement for further investigations to delineate its precise mechanisms and possible therapeutic values, particularly in the field of chronic diseases.

\section{References}

1. De Smet PA (2002) Herbal remedies. N Engl J Med 347: 2046-2056.

2. Reyes-Agüero JA, Aguirre-Rivera JR, Hernandez MH (2005) Systematic notes and detailed description of Opuntia ficus-indica (L.) MILL. (Cactacea). Agrociencia 39: 395-408

3. Pareek OP, Singh RS,Vashishtha BB (2003) Performance of Cactus Pear [Opuntia ficus-indica (L.) Mill.] Clones in Hot Arid Region of India. Journal of the Professional Association for Cactus Development 5: 121-130.

4. Griffith MP (2004) The origins of an important cactus crop, Opuntia ficus-indica (Cactaceae): new molecular evidence. Am J Bot 91: 1915-1921.

5. Saenz C (2000) Processing technologies: an alternative for cactus pea (Opuntia spp.) fruits and cladodes. Journal of Arid Environments 46: 209-225.

6. Inglese P, Basile F, Schirra M (2002) Cactus pear fruit production, in Cacti: Biology and uses. Park S. Nobel, Berkeley, California 163-179.

7. Ahn DK (1998) Illustrated book of Korean medicinal herbs. Kyohak Publishing Company, Seoul, South Korea.

8. Hunt D, Taylor NP, Charles G (2006) The new cactus lexicon. DH Books Milborne Port, UK.

9. Zhao M, Yang N, Yang B, Jiang Y, Zhang G (2007) Structural characterization of water-soluble polysaccharides from Opuntia monacantha cladodes in relation to their anti-glycated activities. Food Chemistry 105: 1480-1486. 
Citation: Osuna-Martínez U, Reyes-Esparza J, Rodríguez-Fragoso L (2014) Cactus (Opuntia ficus-indica): A Review on its Antioxidants Properties and Potential Pharmacological Use in Chronic Diseases. Nat Prod Chem Res 2: 153. doi:10.4172/2329-6836.1000153

10. Trachtenberg S, Mayer AM (1981) Composition and properties of Opuntia ficusindica mucilage. Phytochemistry 20: 2665-2668.

11. Lee EH, Kim HJ, Song YS, Jin C, Lee KT, et al. (2003) Constituents of the stems and fruits of Opuntia ficus-indica var. saboten. Arch Pharm Res 26: 1018-1023.

12. Hernández-Urbiola MI, Pérez-Torrero E, Rodríguez-García ME (2011) Chemical analysis of nutritional content of prickly pads (Opuntia ficus indica) at varied ages in an organic harvest. Int J Environ Res Public Health 8: 1287-1295.

13. Rodríguez-García ME, De Lira C, Hernández-Becerra E, Cornejo-Villegas MA Palacios-Fonseca AJ, et al. (2007) Physicochemical characterization of prickly pads (Opuntia ficus indica) and dry vacuum prickly pads powders as a function of the maturation. Plant Foods Hum Nutr 62: 107-112.

14. Ginestra G, Parker ML, Bennett RN, Robertson J, Mandalari G, et al. (2009) Anatomical, chemical, and biochemical characterization of cladodes from prickly pear [Opuntia ficus-indica (L.) Mill.]. J Agric Food Chem 57: 1032310330.

15. Martinez-Rodríguez MC, Rincón F, Periagon-Castro MJ, Ros-Berruezo GF Lopez G (1993) Dietary fiber components and physiological effects. Spanish Journal of Science and Food Technology 33: 229-246.

16. Feugang JM, Konarski P, Zou D, Stintzing FC, Zou C (2006) Nutritional and medicinal use of Cactus pear (Opuntia spp.) cladodes and fruits. Front Biosci 11: $2574-2589$

17. Nuñez-López MA, Paredes-López O, Reynoso-Camacho R (2013) Functional and hypoglycemic properties of nopal cladodes (O. ficus-indica) at different maturity stages using in vitro and in vivo tests. J Agric Food Chem 61: 10981 10986

18. Chougui N, Tamendjari A, Hamidj W, Hallal S, Barras A, et al. (2013) Oi composition and characterisation of phenolic compounds of Opuntia ficusindica seeds. Food Chem 139: 796-803.

19. Bensadón S, Hervert-Hernández D, Sáyago-Ayerdi SG, Goñi I (2010) Byproducts of Opuntia ficus-indica as a source of antioxidant dietary fiber. Plant Foods Hum Nutr 65: 210-216.

20. Uebelhack R, Busch R, Alt F, Beah ZM, Chong PW (2014) Effects of cactus fiber on the excretion of dietary fat in healthy subjects: a doble blind, randomized, placebo-controlled, crossover clinical investigation. Current Therapeutic Research, Clinical and Experimental 76: 39-44.

21. Saleem M, Kim HJ, Han CK, Jin C, Lee YS (2006) Secondary metabolites from Opuntia ficus-indica var. saboten. Phytochemistry 67: 1390-1394.

22. Tesoriere L, Fazzari M, Allegra M, Livrea MA (2005) Biothiols, taurine, and lipid-soluble antioxidants in the edible pulp of Sicilian cactus pear (Opuntia ficus-indica) fruits and changes of bioactive juice components upon industrial processing. J Agric Food Chem 53: 7851-7855

23. Stintzing FC, Carle R (2005) Cactus stems (Opuntia spp.): a review on their chemistry, technology, and uses. Mol Nutr Food Res 49: 175-194.

24. Zito P, Sajeva M, Bruno M, Rosselli S, Maggio A, et al. (2013) Essential oils composition of two Sicilian cultivars of Opuntia ficus-indica (L.) Mill. (Cactaceae) fruits (prickly pear). Nat Prod Res 27: 1305-1314

25. Formisano C, Senatore F, Bancheva S, Bruno M, Rosselli S (2010) Volatile components from aerial parts of Centaurea spinosociliata Seenus ssp. cristata (Bartl.) Dostál and Centaurea spinosociliata Seenus ssp. spinosociliata growing wild in Croatia. Croatica Chemica Acta 83: 403-408.

26. Trejo-González A, Gabriel-Ortiz G, Puebla-Pérez AM, Huízar-Contreras MD Munguía-Mazariegos MR, et al. (1996) A purified extract from prickly pear cactus (Opuntia fuliginosa) controls experimentally induced diabetes in rats. $J$ Ethnopharmacol 55: 27-33.

27. Alarcon-Aguilar FJ, Valdes-Arzate A, Xolalpa-Molina S, Banderas-Dorante T, Jimenez-Estrada M, et al. (2003) Hypoglycemic Activity of Two Polysaccharides Isolated from Opuntia ficus-indica and O. Streptacantha. Proc West Pharm Soc 46: $139-142$.

28. Laurenz JC, Collier CC, Kuti JO (2003) Hypoglycaemic effect of Opuntia lindheimeri Englem in a diabetic pig model. Phytother Res 17: 26-29.

29. Luo C, Zhang W, Sheng C, Zheng C, Yao J, et al. (2010) Chemical composition and antidiabetic activity of Opuntia Milpa Alta extracts. Chem Biodivers 7: 28692879.

30. Zhao LY, Lan QJ, Huang ZC, Ouyang LJ, Zeng FH (2011) Antidiabetic effect of a newly identified component of Opuntia dillenii polysaccharides. Phytomedicine 18: $661-668$.
31. Hahm SW, Park J, Son YS (2011) Opuntia humifusa stems lowers blood glucose and cholesterol levels in streptozotocin-induced diabetic rats. Nutr Res 31: 479-487

32. Becerra-Jiménez J, Andrade-Cetto A (2012) Effect of Opuntia streptacantha Lem. on alpha-glucosidase activity. J Ethnopharmacol 139: 493-496.

33. Roman-Ramos R, Flores-Saenz JL, Alarcon-Aguilar FJ (1995) Antihyperglycemic effect of some edible plants. J Ethnopharmacol 48: 25-32.

34. Linarès E, Thimonier C, Degre M (2007) The effect of NeOpuntia on blood lipid parameters--risk factors for the metabolic syndrome (syndrome $\mathrm{X}$ ). Adv Ther 24: $1115-1125$.

35. López-Romero P, Pichardo-Ontiveros E, Avila-Nava A, Vázquez-Manjarrez N, Tovar AR, et al. (2014) The Effect of Nopal (Opuntia Ficus Indica) on Postprandial Blood Glucose, Incretins, and Antioxidant Activity in Mexican Patients with Type 2 Diabetes after Consumption of Two Different Composition Breakfasts. J Acad Nutri Diet pii: S2212-2672: 01021-1.

36. Godard MP, Ewing BA, Pischel I, Ziegler A, Benedek B, et al. (2010) Acute blood glucose lowering effects and long-term safety of OpunDia supplementation in pre-diabetic males and females. J Ethnopharmacol 130: 631-634.

37. Van Proeyen K, Ramaekers M, Pischel I, Hespel P (2012) Opuntia ficusindica ingestion stimulates peripheral disposal of oral glucose before and afte exercise in healthy men. Int J Sport Nutr Exerc Metab 22: 284-291.

38. Deldicque L, Van Proeyen K, Ramaekers M, Pischel I, Sievers H, et al. (2013) Additive insulinogenic action of Opuntia ficus-indica cladode and fruit skin extract and leucine after exercise in healthy males. J Int Soc Sports Nutri 10: 45.

39. Kaastra B, Manders RJ, Van Breda E, Kies A, Jeukendrup AE, et al. (2006) Effects of increasing insulin secretion on acute postexercise blood glucose disposal. Med Sci Sports Exerc 38: 268-275

40. Grube B, Chong PW, Lau KZ, Orzechowski HD (2013) A natural fiber complex reduces body weight in the overweight and obese: a double-blind, randomized, placebo-controlled study. Obesity (Silver Spring) 21: 58-64.

41. Osorio-Esquivel O, Ortiz-Moreno A, Garduño-Siciliano L, Alvarez VB Hernández-Navarro MD (2012) Antihyperlipidemic effect of methanolic extract from Opuntia joconostle seeds in mice fed a hypercholesterolemic diet. Plant Foods Hum Nutr 67: 365-370.

42. Tesoriere L, Butera D, Pintaudi AM, Allegra M, Livrea MA (2004) Supplementation with cactus pear (Opuntia ficus-indica) fruit decreases oxidative stress in healthy humans: a comparative study with vitamin $\mathrm{C}$. Am J Clin Nutri 80: 391-395.

43. Oh PS, Lim KT (2006) Glycoprotein $(90 \mathrm{kDa})$ isolated from Opuntia ficusindica var. saboten MAKINO lowers plasma lipid level through scavenging of intracellular radicals in Triton WR-1339-induced mice. Bio Pharm Bull 29: 1391 1396.

44. Zhao LY, Huang W, Yuan QX, Cheng J, Huang ZC, et al. (2012) Hypolipidaemic effects and mechanisms of the main component of Opuntia dillenii Haw. polysaccharides in high-fat emulsion-induced hyperlipidaemic rats. Food Chem 134: 964-971.

45. Perfumi M, Tacconi R (1996) Effect of Opuntia ficus-indica flower infusion on urinary and electrolyte excretion in rats. Fitoterapia 67: 459-464.

46. Galati EM, Tripodo MM, Trovato A, Miceli N, Monforte MT (2002) Biological effect of Opuntia ficus indica (L.) Mill. (Cactaceae) waste matter. Note I: diuretic activity. J Ethnopharmacol 79: 17-21.

47. Park EH, Kahng JH, Lee SH, Shin KH (2001) An anti-inflammatory principle from cactus. Fitoterapia 72: 288-290.

48. Sreekanth D, Arunasree MK, Roy KR, Chandramohan Reddy T, Reddy GV, et al. (2007) Betanin a betacyanin pigment purified from fruits of Opuntia ficusindica induces apoptosis in human chronic myeloid leukemia Cell line-K562. Phytomedicine 14: 739-746.

49. Palevitch D, Earon G, Levin I (1993) Treatment of benign prostatic hypertrophy with Opuntia ficus-indica (L.) Journal of Herbs, Spices, and Medicine Plant 2: $45-49$.

50. Wie MB (2000) Protective effects of Opuntia ficus-indica and Saururus Chinensis on free-radical induced neuronal injury in mouse cortical cell cultures. Yakhak Hoeji 44: 613-619.

51. Dok-Go H, Lee KH, Kim HJ, Lee EH, Lee J, et al. (2003) Neuroprotective effects of antioxidative flavonoids, quercetin, (+)-dihydroquercetin and quercetin 3 -methyl ether, isolated from Opuntia ficus-indica var. saboten. Brain Res 965 130-136.

52. Kim JM, Kim DH, Park SJ, Park DH, Jung SY, et al. (2010) The n-butanolic extract of Opuntia ficus-indica var. saboten enhances long-term memory in the passive avoidance task in mice. Progress in Neuro-Psychopharmacology Biological Psychiatry 34: 1011-1017. 
Citation: Osuna-Martínez U, Reyes-Esparza J, Rodríguez-Fragoso L (2014) Cactus (Opuntia ficus-indica): A Review on its Antioxidants Properties and Potential Pharmacological Use in Chronic Diseases. Nat Prod Chem Res 2: 153. doi:10.4172/2329-6836.1000153

53. Kim JH, Park SM, Ha HJ, Moon CJ, Shin TK, et al. (2006) Opuntia ficus-indica attenuates neuronal injury in in vitro and in vivo models of cerebral ischemia. $J$ Ethnopharmacol 104: 257-262.

54. Lee MH, Kim JY, Yoon JH, Lim HJ, Kim TH, et al. (2006) Inhibition of nitric oxide synthase expression in activated microglia and peroxynitrite scavenging activity by Opuntia ficus indica var. saboten. Phytother Res 20: 742-747.

55. Park SH, Sim YB, Han PL, Lee JK, Suh HW (2010) Antidepressant-like Effect of Kaempferol and Quercitirin, Isolated from Opuntia ficus-indica var. saboten. Exp Neurobiol 19: 30-38.

56. Brieger K, Schiavone S, Miller FJ Jr, Krause KH (2012) Reactive oxygen species: from health to disease. Swiss Med Wkly 142: w13659.

57. Liu RH (2003) Health benefits of fruit and vegetables are from additive and synergistic combinations of phytochemicals. Am J Clin Nutr 78: 517S-520S.

58. Fernández-López JA, Almela L, Obón JM, Castellar R (2010) Determination of antioxidant constituents in cactus pear fruits. Plant Foods Hum Nutr 65: 253-259.

59. Kuti JO (2004) Antioxidant compounds from four Opuntia cactus pear fruit varieties. Food Chemistry 85: 527-533.

60. Alimi H, Hfaeidh N, Bouoni Z, Sakly M, Ben Rhouma K (2012) Protective effect of Opuntia ficus indica $\mathrm{f}$. inermis prickly pear juice upon ethanol-induced damages in rat erythrocytes. Alcohol 46: 235-243.

61. Chavez-Santoscoy RA, Gutierrez-Uribe JA, Serna-Saldívar SO (2009) Phenolic composition, antioxidant capacity and in vitro cancer cell cytotoxicity of nine prickly pear (Opuntia spp.) juices. Plant Foods Hum Nutr 64: 146-152.

62. Galati EM, Mondello MR, Lauriano ER, Taviano MF, Galluzzo M, et al. (2005) Opuntia ficus indica (L.) Mill. fruit juice protects liver from carbon tetrachlorideinduced injury. Phytother Res 19: 796-800.

63. Brahmi D, Ayed Y, Hfaiedh M, Bouaziz C, Ben Mansour H, et al. (2012) Protective effect of cactus cladode extract against cisplatin induced oxidative stress, genotoxicity and apoptosis in balb/c mice: combination with phytochemical composition. BMC Complementary and Alternative Medicine 12: 1-14.
64. Brahmi D, Bouaziz C, Ayed Y, Ben Mansour H, Zourgui L, et al. (2011) Chemopreventive effect of cactus Opuntia ficus indica on oxidative stress and genotoxicity of aflatoxin B1. Nutr Metab (Lond) 8: 73

65. Stintzing FC, Schieber A, Carle R (2001) Phytochemical and nutritional significance of cactus pear. European Food Research and Technology 212 396-407.

66. Lee JA, Jung BG, Lee BJ (2012) Inhibitory effects of Opuntia humifusa on 7 12-dimethyl- benz[a]anthracene and 12-O-tetradecanoylphorbol-13- acetate induced two-stage skin carcinogenesis. Asian Pac J Cancer Prev 13: 46554660 .

67. Avila-Nava A, Calderón-Oliver M, Medina-Campos OM, Zou T, Gu L, et al. (2014) Extract of cactus (Opuntia ficus indica) cladodes scavenges reactive oxygen species in vitro and enhances plasma antioxidant capacity in humans. Journal of Functional Foods 10: 13-24.

68. Wiese J, McPherson S, Odden MC, Shlipak MG (2004) Effect of Opuntia ficus indica on symptoms of the alcohol hangover. Arch Intern Med 164: 1334-1340.

69. Pittler MH, Verster JC, Ernst E (2005) Interventions for preventing or treating alcohol hangover: systematic review of randomised controlled trials. BMJ 331: 1515-1518.

70. Aguilera-Barreiro ML, Rivera-Márquez JA, Trujillo-Arriaga HM, Tamayo Y, et al (2013) Intake of dehydrated nopal (Opuntia ficus indica) improves bone mineral density and calciuria in adult Mexican women. Food Nutri Res 57.

71. Kleiner O, Cohen Z, Mares AJ (2002) Low colonic obstruction due to Opuntia ficus indica seeds: the aftermath of enjoying delicious cactus fruits. Acta Paediatr 91: 606-607.

72. Gagnier JJ, DeMelo J, Boon H, Rochon P, Bombardier C (2006) Quality of reporting of randomized controlled trials of herbal medicine interventions. Am J Med 119: 800 